\title{
A LGBTIFOBIA PRESENTE NO INTERIOR DE UMA ESCOLA PÚBLICA EM SÃO GONÇALO - RJ
}

\author{
LGBTIFOBIA PRESENT INSIDE A PUBLIC SCHOOL IN SÃO GONÇALO - RJ
}

\author{
Renan Corrêa ${ }^{1}$, Denize Sepulveda², José Antônio Sepulveda ${ }^{3}$, Daniel Carvalho de \\ Almeida Lima ${ }^{4}$
}

\begin{abstract}
1Universidade do Estado do Rio de Janeiro ï GESDI ï Programa de Pós Graduação em Educação ï Processos Formativos e Desigualdades Sociais, Brasil, naner_rj@hotmail.com ï ORCID: https://orcid.org/0000-0003-4206-358X

2Universidade do Estado do Rio de Janeiro ï Programa de Pós Graduação em Educação ï Processos Formativos e Desigualdades Sociais, Brasil, denizesepulveda@hotmail.com ï ORCID: https://orcid.org/0000-0001-9049-5200

3Universidade Federal Fluminense ï Programa de Pós Graduação em Educação ï Brasil, jamsepulveda3@hotmail.com ï ORCID: https://orcid.org/0000-0003-4460-7704

${ }^{4}$ Mestrando pelo Curso PROFMAT Universidade do Estado do Rio de Janeiro - RJ, sgo.danielc@gmail.com ï ORCID: https://orcid.org/0000-0003-1580-6077
\end{abstract}

ARTICLE INFO

Article history:

Received 2020-06-01

Accepted 2020-06-20

Available online $2020-06-20$
Palavras-chave: Práticas, LGBTfobia, Preconceitos.

Keywords: Practices, LGBTphobia, Prejudices.

RESUMO. Este trabalho de pesquisa foi desenvolvido em um Colégio da Rede Estadual de Educação do Rio de Janeiro, no município de São Gonçalo. Tivemos como objetivos saber se no espaço da escola em questão ocorrem práticas conservadoras, preconceituosas e discriminatórias contra alunxs LGBTIS+ e investigarmos quais são estas práticas, como elas se desenvolvem e se os valores religiosos de professorxs e funcionárixs interferem nelas. Baseia-se em uma abordagem qualitativa, o referencial teórico-metodológico é a Pesquisa Nos/Dos/Com os Cotidianos (Alves 2002). Para a análise dos dados e leitura das narrativas dos sujeitos foi utilizado o Paradigma Indiciário de Carlo Ginzburg (1989). Foi possível perceber que ocorrem práticas LGBTIfóbicas na escola pesquisada, ou seja, xs alunxs LGBTIS+, sofrem práticas discriminatórias por parte de outrxs alunxs, professorxs e funcionárixs. Outro indício também colhido, porém, a partir do método de observação, foram as atitudes lesbofóbicas de um inspetor que chama a atenção de um casal de lésbicas abraçadas no pátio, mas desconsidera um casal heterossexual abraçados próximo a ele, não chamando a atenção deste casal. Sendo assim, podemos perceber pistas, indícios e sinais de práticas LGBTIfóbicas ocorrendo na escola.

ABSTRACT. This research work was developed in a College of the State Education Network of Rio de Janeiro, in the municipality of São Gonçalo. We had as objectives to know if in the space of the school in question conservative, prejudiced and discriminatory practices occur against LGBT + students and to investigate what these practices are, how they develop and if the religious values of teachers and staff interfere in them. Based on a qualitative approach, the theoretical-methodological framework is the Nos / Dos / Com Cotidianos Research (Alves 2002). For the analysis of the data and reading of the subjects' narratives the Carlo Ginzburg (1989) Paradigm was used. It was possible to perceive that LGBTIphobic practices occur in the researched school, in other words, the LGBTIS + students, suffer discriminatory practices from other students, teachers and employees. Another indication also collected, however, from the observation method, were the lesbophobic attitudes of an inspector who calls the attention of a lesbian couple embraced in the courtyard, but disregards a heterosexual couple embraced next to him, not calling the attention of this couple. Thus, we can perceive clues, evidence and signs of LGBTIphobic practices occurring at school. 


\section{INTRODUÇÃO}

As questões de gêneros e sexualidades tem ganhado muita atenção nas mais variadas esferas da sociedade. No campo educacional, há se assim podemos dizer uma guerra onde de um lado temos $x^{1}$ conservadorxs a favor de que a discussão de gêneros não ocorra dentro dos espaços escolares, um exemplo é o Movimento Escola Sem Partido, de outro, há um pensamento mais progressista, lutando para que essas discussões possam ocorrer, com a finalidade de que haja mais igualdade entre os gêneros e menos preconceito.

Segundo (Bonazzi, 2000), fica mais fácil entender o conceito de conservador pela variedade de significados atribuídos ao adjetivo, do que entender o substantivo conservadorismo pela dificuldade de determinar a sua natureza e os seus fins. A inexistência de uma teoria política comum que defina xs conservadorxs e a dificuldade $d x s$ conservadorxs em sistematizar suas próprias ideias complica mais ainda a compreensão do termo. Com isso, o uso da palavra entra no cotidiano com sentidos variados, ganhando vida e sendo apropriada, muitas vezes, como forma de xingamento.

Libâneo (1994) diz que a pedagogia progressista designa as tendências que, partindo de uma análise crítica das realidades sociais, sustentam implicitamente as finalidades sociopolíticas da educação. Essas tendências são denominadas como: Pedagogia Progressista Libertadora, Pedagogia Progressista Libertária e Pedagogia Críticosocial dos Conteúdos e Histórico-Crítica.

Sendo assim, de acordo com (Sepulveda e Sepulveda, 2016), desde 2014, período da discussão e aprovação do atual Plano Nacional de Educação, o Movimento Escola Sem Partido vem propondo projetos de lei que estão sendo apresentados nos estados e municípios com nomes variados, mas com os mesmos objetivos, tendo como referência o PL 2731/2015 proposto pelo deputado Eros Biondini, do Partido Trabalhista Brasileiro de Minas Gerais (PTB-MG), que, "Altera a Lei 13.005, de 25 de junho de 2014, que estabelece o PNE e dá outras providências". Este novo projeto de lei altera o PNE para "dispor sobre a proibição do uso da ideologia de gênero na educação nacional". Cabe ressaltar que este projeto de lei foi arquivado no final de 2018.

Em 2019, mais precisamente no primeiro dia de trabalho na câmara dos deputados, a deputada federal Bia Kicis do Partido Social Liberal do Distrito Federal, apresentou uma nova versão do projeto Escola Sem Partido, sendo esta segunda proposta mais rigorosa, onde xs alunxs estão livres para filmar e denunciar xs professorxs que descumprirem a lei.

\footnotetext{
${ }^{1}$ Faço o uso do ñXò nas palavras, como demarcação política, e do ponto de vista linguístico e gramatical é uma forma de usar uma linguagem escrita que expresse maior igualdade entre homens e mulheres, pois normalmente só o gênero masculino é privilegiado. Desta forma, para romper com essa supremacia do gênero masculino na escrita, optei pelo uso do ñXò (SEPULVEDA; SEPULVEDA, 2016a).
} 
Esta nova versão vem a ser a PL 246/2019.

É necessário frisar que nos cotidianos das escolas, é grande a diversidade presente, porém, há pessoas que não conseguem conviver bem com tantas diferenças. Com a finalidade de saber como se dão essas relações no ambiente escolar, já que este é um espaço tão diverso, fez-se necessário desenvolver uma pesquisa em um Colégio da Rede Estadual de Educação do Rio de Janeiro, no município de São Gonçalo, com o objetivo de saber se ocorrem práticas conservadoras, preconceituosas e discriminatórias contra alunxs LGBTIS $+{ }^{2}$ (Lésbicas, Gays, Bissexuais, Travestis, Transexuais, Transgêneros, Intersexuais) e investigarmos quais são estas práticas e como elas se desenvolvem. Assim, foi necessário observarmos o dia-a-dia entre professorxs, funcionárixs e alunxs.

A partir de observações tentamos identificar se alunxs, sofriam processos de exclusão, por conta de suas orientações sexuais. E em caso positivo, quem praticava. Essas práticas excludentes não são exclusivas apenas de uma escola, afinal de contas todo espaço escolar é heterogêneo. Desta forma, investigamos como se davam as relações dos alunos LGBTIS com xs demais colegas, professores(as) e funcionários(as) da instituição escolar.

Os processos de discriminação costumam ter, na sociedade ocidental, uma sutileza que dificulta sua identificação. Eles se encontram, muitas vezes, nas r̃entrelinhasò dos discursos, nas rotinas, nos costumes, perpetuando-se nas relações sociais. É uma ñáticaò silenciosa tão poderosa que faz com que esses processos pareçam naturais. (FACCO, 2011, p.19).

Dessa forma, do ponto de vista procedimental, para desenvolver este trabalho, utilizamos uma abordagem qualitativa de pesquisa desenvolvida por meio de observação/presença continuada no local, pois o tema a ser investigado é complexo e precisa ser abordado considerando-se essa complexidade. Essa modalidade de pesquisa, em que o pesquisador mantém um contato direto e prolongado com a situação estudada no trabalho de campo, é a mais indicada. O contato do pesquisador nos/dos/com os cotidianos, com os sujeitos pesquisados, no trabalho de campo, permite recolher diversas informações, que são pistas, indícios e sinais, muitas vezes inesperados, que ajudam a perceber muitas das relações que atravessam o problema de pesquisa. $O$ cotidiano exige ver além daquilo que os outros já viram, e que o pesquisador:

\footnotetext{
${ }^{2}$ É necessário enfatizar que acrescentamos a letra r̂́Sòa referida sigla por considerarmos que xs simpatizantes e parceiros dessas identidades também vivenciam em seus cotidianos procedimentos de discriminação, preconceitos e exclusão, são procedimentos diferentes, não são os mesmos, pois nenhum indivíduo sente esses processos da mesma forma, contudo sofrem essas ações. De acordo com Goffman (1988), as pessoas que compartilham da vida de indivíduos estigmatizados, que sofrem processos de discriminação e preconceito, são definidas como suas iguais e denominadas de ñnformadasò São sujeitos cuja situação de vida ou militância os levou a serem simpatizantes da causa e que por isso possuem aceitação do grupo, por outro lado também sofrem da maior parte das privações, preconceitos e discriminações típicas do grupo pelo qual assumiram conviver e militar.
} 
(...) seja capaz de mergulhar inteiramente em uma determinada realidade buscando referências de sons, sendo capaz de engolir, sentindo a variedade de gostos, caminhar tocando coisas e pessoas e me deixando tocar por elas, cheirando odores que a realidade coloca a cada ponto do caminho diário. (ALVES, 2002, p. 17).

Além do mergulho que é um dos movimentos das pesquisas nos/dos/com os cotidianos, existem mais três: virar de ponta-cabeça, beber em todas as fontes, narrar a vida e literaturizar a ciência.

O segundo movimento a ser feito é compreender que o conjunto de teorias, conceitos e noções que herdamos das ciências criadas e desenvolvidas na chamada modernidade e que continuam sendo um recurso indispensável, não é só apoio e orientador da rota a ser trilhada, mas, também e cada vez mais, limite ao que precisa ser tecido. Para nomear esse processo de compreensão de que é limite aquilo que nos habituamos a ver como apoio, parafraseando o historiador Hill (1987), que estuda momentos anteriores de grandes mudanças, estou usando a ideia de virar de ponta-cabeça.

Para ampliar os movimentos necessários, creio que o terceiro deles, incorporando a noção de complexidade [...], vai exigir a ampliação do que é entendido como fonte e a discussão sobre os modos de lidar com a diversidade, o diferente e 0 heterogêneo. Creio poder chamar a esse movimento beber em todas as fontes.

Por fim, vou precisar assumir que para comunicar novas preocupações, novos problemas, novos fatos e novos achados, é indispensável uma nova maneira de escrever, que remete a mudanças muito mais profundas. A esse movimento talvez se pudesse chamar de narrar a vida e literaturizar a ciência. (ALVES, 2002, p. 1516).

Nosso contato com o cotidiano escolar, com xs sujeitxs pesquisadxs, no trabalho de campo, permitiu recolher diversas informações por vezes inesperadas, que nos ajudaram a perceber algumas relações que atravessam a pesquisa. E para a leitura desses dados, que são pistas, indícios e sinais, utilizamos o paradigma indiciário de (Carlo Ginzburg, 1989). autor nos remete à necessidade de se trabalhar sobre os indícios que a realidade apresenta. Ler pistas e sinais, tentar entender através desses alguns significados daquilo que não temos capacidade de compreender de outro modo, captar neles informações do real não acessíveis pelos meios tradicionais de pesquisa; é esse o fundamento do paradigma indiciário, que segundo o autor, foi concebido e atesta as influências deste paradigma.

A partir das percepções e observações já realizadas por outrxs pesquisadorxs, (LUZ, 2018; SEPULVEDA, 2012), foi possível identificar no colégio investigado que alguns alunos e alunas, sofrem processos de exclusão, por conta de suas orientações sexuais. Tais processos são praticados por outrxs alunxs, por professorxs e funcionárixs.

Vale ressaltar aqui que as situações vividas nos levaram ao tema pesquisado. Nosso desconforto se deu em relação a algumas práticas tecidas em algumas escolas em relação aos alunos gays, as lésbicas, axs bissexuais e axs transgênerxs, o que nos levou a perceber o assunto como um tema significativo de estudo, tornando-se de extrema importância, pois partimos do princípio que as práticas discriminatórias deferidas contra xs alunxs LGBTIS+ nas escolas podem influenciar de maneira negativa no desenvolvimento da autoestima, interferindo assim, em suas atuações nos vários espaços sociais. 


\section{Homofobia aqui na escola? Nunca presenciei ou pratiquei!}

Muitxs funcionárixs e professorxs, quando entrevistadxs, afirmavam desconhecer qualquer prática homofóbica na escola, alguns outrxs alegavam ter presenciado algumas ações discriminatórias contra alunxs LGBTIS+ e dentre estxs há aquelxs que declaram ter observado, porém, as minimizam informando que eram somente algumas brincadeiras.

A funcionária đ̃Yở, quando foi questionada sobre o que é homofobia e/ou lesbofobia, respondeu da seguinte forma: É a pessoa não respeitar o indivíduo que é do outro sexo, ou seja, do sexo oposto 4 .

Essa fala dá indícios do desconhecimento do que vem a ser a homofobia, e tal questão pode estar aliada a falta de uma formação adequada, pois na maioria das escolas não são dadas capacitações a funcionárixs, não se dialoga sobre a temática das diferenças de gêneros e sexualidades. Levanto como indício que tal desconhecimento beira a alienação ${ }^{5}$ em relação ao assunto principal desta monografia.

A LGBTIfobia ${ }^{6}$ está presente em nosso cotidiano, nos mais diversos espaços em que os seres humanos habitam e para que a LGBTlfobia se manifeste, ou melhor, para que as pessoas expressem a LGBTIfobia não há necessidade de um contato direto e real com o receptor das práticas discriminatórias.

A não necessidade de contato com o objeto do preconceito para que este surja mostra que ele pode se dar sem conexão nenhuma com a realidade, mas assim temos de supor que os estereótipos apresentados no preconceito ou são produções individuais ou são produções culturais; como a sua expressão em geral é coletiva, ou seja, se repete da mesma forma em diversos indivíduos, podemos deduzir que os indivíduos se apropriam de algumas representações culturais para que, junto à hostilidade dirigida ao objeto, configurem o preconceito. (CROCHÍK, $1996 \mathrm{~s} / \mathrm{p})$.

Para o funcionário ñAò todxs xs alunxs são aceitos da mesma forma, não havendo distinção ou acepção, seja de cor, raça, religião, gênero e orientação sexual. $A$ escola age

\footnotetext{
${ }^{3}$ Utilizamos letras aleatórias para nos referirmos e nomear xs professorxs, funcionárixs e alunxs, pois desta maneira, preservamos suas identidades.

${ }^{4}$ Por opção metodológica, os trechos dos relatos orais estão em itálico, pois assim se diferenciam das citações teóricas.

${ }^{5}$ A palavra alienação vem do Latim r̃alienusò que significa r̃de foraò Portanto, a alienação é estar alheio aos acontecimentos sociais, ou achar que está fora de sua realidade.

${ }^{6}$ A LGBTfobia é a hostilidade geral, psicológica e social em relação aquelxs que, supostamente, possuem desejo ou têm atividades sexuais com pessoas do mesmo sexo (práticas homoeróticas). A LGBTfobia rejeita, também, todxs os indivíduos que não aceitam o papel de gênero predeterminado no nascimento, ou seja, recusa todos os comportamentos de gêneros que não estão normatizados de acordo com o sexo biológico. Trata-se de preconceito em relação a sexualidade que foge das normas heterossexuais e da identidade cisgênera, organizando uma hierarquização das sexualidades e das identidades de gêneros. A cisgeneridade é definida como uma pessoa cuja identidade de gênero coincide com o gênero atribuído no nascimento.
} 
com tranquilidade e os alunos homossexuais são recebidos nesta instituição com o mesmo respeito que os demais alunos.

Já de acordo com xs estudantes gays e lésbicas, há sim práticas discriminatórias contra elxs dentro do espaço escolar, principalmente por parte de professorxs e funcionárixs e que infelizmente não há intervenção por parte da direção, para que tais práticas sejam ao menos diminuídas.

(...) Escola não apenas entende diferenças e desigualdades, como as produz. Ela possui aquele m̃nodeloòde estudante idealizado, que corresponde, com perfeição, ao que se espera dele. Não sabendo lidar com os estudantes que não correspondem a esse modelo, a escola acaba por contribuir para introjetar em todos, cada vez mais, o pensamento discriminatório. Os preconceitos estão de tal forma arraigados no pensamento social que, muitas vezes, os professores reproduzem hoje os discursos de discriminação sem perceber. (FACCO, 2011, p. 27).

Com base também nos relatos realizados por alunxs da instituição pesquisada, percebe-se que são exercidas condutas LGBTIfóbicas. Segundo a narrativa da aluna r̃à uma funcionária da escola disse que ela precisava de uma igreja, pra se libertar, ou seja, deixar de ser lésbica. Uma funcionária disse que eu estava precisando ir para a igreja só por eu ser lésbica.

O aluno r̃Rò relatou o seguinte acontecimento: Uma vez eu estava dançando na escola e a tia que faz a limpeza disse para mim: olha como Satanás está te usando, você está dançando aí todo afeminado, vá para a igreja menino. Muitas vezes os valores religiosos, podem ter forte influência nessas práticas preconceituosas, afinal usa a lógica do pecado com o intuito de culpar o homossexual.

Mediante a tal exposição, percebe-se uma grande necessidade de elaborar projetos de intervenções, com objetivo de promover a igualdade social e a não discriminação por conta da orientação sexual, afinal não é difícil esbarrar com membros de comunidades escolares sem saber o que significa o termo homofobia, que inclusive é um conceito inicial das fobias relativas a comunidade LGBTIS+. Assim, assistimos cotidianamente tais alunxs sendo submetidos a práticas discriminatórias motivados pelos sentimentos e discursos LGBTIfóbicos.

\section{Separem-se, isso aqui é uma escola!}

Escreveremos agora menção a um fato por nós observado na instituição pesquisada. Tudo transcorria bem no horário do intervalo, alunxs no pátio conversando e um inspetor passou por duas meninas que estavam sentadas no chão, no corredor onde elxs, os estudantes LGBTIS+ costumam se reunir. As meninas estavam uma recostada sobre a outra, ele passou por elas e pediu para que se separassem, pois, segundo o inspetor: ali é uma escola e não é lugar para aquilo. Em seguida ele saiu, e no caminho dele havia um casal heterossexual na mesma posição das meninas, contudo, ele continuou andado, olhou 
e nada disse sobre a postura dos dois. De acordo com (Louro, 2008, p.21), ra sexualidade permanece como alvo privilegiado da vigilância e do controle das sociedades. Ampliam-se e diversificam-se suas formas de regulação, multiplicam-se as instâncias e as instituições que se autorizam a ditar-Ihe normasò

Ainda de acordo com (Louro, 2008) a escola é um local que indica quem são xs alunxs que serão os exemplos a serem seguidos e a não serem seguidos de uma forma naturalizada:: Nesta visão, é necessário penalizar, chamar a atenção, enquadrar e até mesmo marginalizar aquelxs que não servem como exemplo.

Quando chegamos na instituição escolar, como estudantes, aprendemos um número grande e bem variado de regras, e também é delimitado o espaço das meninas e dos meninos. Os rapazes vão para a quadra jogar futebol, enquanto as meninas ficam no pátio conversando com suas amigas, brincando de boneca ou se divertindo com alguma îbrincadeira de meninaò Quando uma criança tenta ou quebra essa barreira imposta é bem provável que será repreendida por colegas e/ou professorxs que foram condicionadxs a segregar os espaços e diferenciá-los em lugar para meninas e lugar para meninos.

De acordo com (Sepulveda, 2012, p.152), ñivemos em uma sociedade que tem a necessidade de se enquadrar em padrões, a fim de definir e delimitar os espaços onde os sujeitos podem estarò

[...] os gêneros são a primeira marcação identitária e de diferenças a que estamos
expostos, ocorrendo antes mesmo de nascermos. Isso porque nascemos num
mundo já organizado discursivamente e estabelecido na relação saber-poder. A
pergunta ré menino ou é meninaò inicia uma definição e uma diferença que nos
enquadra, que nos marca, que nos organiza e que precisa de investimento para a
sua concretização. Butler (2004) argumenta que, ao tratar essa sujeição e
regulação ao gênero como algo que antecede ao nosso nascimento e marca
nossas identidades, é importante levar em conta duas advertências advindas de
Foucault. Por um lado, a ideia de que o poder regulador não atua somente sobre
esses sujeitos preexistentes, mas que ele forma o sujeito e, neste sentido, ele é
produtivo. Por outro lado, estar sujeito a essas normas de gênero e sexualidade é
também estar subjetivado por elas, num constante processo de construção.
(FERRARI, 2010, p. 256).

Sendo o gênero um conceito elaborado, histórica e culturalmente, as estruturas e construções sociais relacionadas a tal conceito estão rentranhadasò e rentrelaçadasò em nosso cotidiano, seja na maneira como classificamos as coisas, a forma como escolhemos nos vestir, falar, andar, sobre o que pensar, do que ou de quem gostar e principalmente de como devemos nos portar perante a sociedade.

Gênero [...] é um dispositivo cultural, constituído historicamente, que classifica e posiciona o mundo a partir da relação entre o que se entende como feminino e masculino. É um operador que cria sentido para as diferenças percebidas em nossos corpos e articula pessoas, emoções, práticas e coisas dentro de uma estrutura de poder. (LINS; MACHADO; ESCOURA, 2016, p. 10). 
Os assuntos acerca das questões disciplinares dos corpos e como ele foi moldado e manipulado pelas instituições políticas e pela sociedade, possuem um lugar fundamental nas análises de Michel Foucault. Dentro deste assunto, ele nos traz conceitos importantíssimos, como ñpoder disciplinarò r̃corpo adestradoòe r̃corpo manipulávelò

Segundo (Foucault, 1979) o poder disciplinar não é um aparelho nem uma instituição, é um dispositivo, um mecanismo, ou seja, um instrumento de poder usado por essas instituições. É um tipo de disciplina que trabalha o corpo dos homens, manipula seus elementos, produz seu comportamento, enfim, fabrica o tipo de homem necessário ao funcionamento e à manutenção da sociedade. A disciplina fabrica assim corpos submissos, corpos dóceis.

O corpo é objeto e alvo do poder. O corpo aqui é algo que se modela, se treina, que obedece, responde e se torna hábil. Ainda segundo (Foucault, 1979), não se trata de cuidar do corpo em massa, como se fosse uma unidade indissociável, mas de trabalhá-lo detalhadamente, de exercer sobre ele uma coerção, de mantê-lo ao mesmo nível da mecânica, ou seja, Foucault refere-se a movimentos, gestos, atitude e rapidez, um poder total sobre o corpo. O corpo humano entra numa m̃maquinariaòde poder que o esquadrinha, o desarticula e o recompõe.

Acreditamos que a escola seja um local onde os corpos estão expostos, para serem moldados e construídos socialmente, seguindo as regras e normas de padrões já préestabelecidos. E é através dessa construção forçada, destes corpos, que vão se produzindo e reproduzindo as diferenças e as desigualdades.

Em nossa sociedade, devido à hegemonia branca, masculina, heterossexual e cristã, têm sido nomeados e nomeadas como diferentes aqueles e aquelas que não compartilham desses atributos. A atribuição da diferença é sempre historicamente contingente ela é dependente de uma situação e de um momento particulares. (LOURO, 1997, p.49 e 50).

Assim, a nossa percepção é que muitos espaços escolares se tornam instituições com um grau elevado de práticas discriminatórias e que não tem conhecimento de como lidar com as diferenças que estão presentes em seus cotidianos. No caso sobredito, percebemos e levantamos como pistas que o inspetor escolar em questão tomou uma atitude extremamente discriminatória com as meninas, sinalizando que o mesmo não sabe lidar com as diferenças relativas as sexualidades presentes na escola pesquisada. Cabe ainda ressaltar que as jovens não eram um casal, eram somente duas amigas, mas provavelmente por uma delas ser lésbica, a prática lesbofóbica, tenha ocorrido.

Estes casos ocorrem a partir da intolerância das pessoas, por não saberem lidar com a diferença dxs outrxs. Aquelxs que fogem aos padrões heteronormativos, xs que vão contra as r̃dominações de poder estabelecidasò são discriminadxs, postos a marginalidade e até vistxs como r̃estranhxsòpor aquelxs que se rencontram no poderò 
Do mesmo modo que a xenofobia, o racismo ou o antissemitismo, a homofobia é uma manifestação arbitrária que consiste em designar o outro como contrário, inferior ou anormal; por sua diferença irredutível, ele é posicionado à distância, fora do universo comum dos humanos. Crime abominável, amor vergonhoso, gosto depravado, costume infame, paixão ignominiosa, pecado contra a natureza, vício de Sodoma ï outras tantas designações que, durante vários séculos, serviram para qualificar o desejo e as relações sexuais ou afetivas entre pessoas do mesmo sexo. Confinado no papel do marginal ou excêntrico, o homossexual é apontado pela norma social como bizarro, estranho ou extravagante. (BORRILLO, 2010, p. 13 e 14.).

Essas dominações de poder estão e são tão bem estabelecidas no cotidiano da nossa sociedade, os carinhos e abraços de um casal heterossexual no ambiente escolar são normais e visto com naturalidade, uma vez que se enquadram no binarismo dominante, macho e fêmea. Quando se trata de duas pessoas do mesmo sexo, neste caso de duas garotas, que expressam afeto da mesma forma, mesmo não se tratando de um casal de namoradas, foram repreendidas, pois não é autorizado em nossa sociedade, pessoas do mesmo sexo demonstrarem publicamente afeto e carinho, visto que não se enquadram na lógica binária dominante. Situações como estas, desestimulam alunxs, afastando-xs do processo de escolarização (SEPULVEDA, 2012).

\section{Estou feliz por você estar aqui, vai nos ajudar a combater a homofobia na escola.}

Ao chegarmos na escola passamos algumas semanas só observando como se dava o convívio dxs membros da comunidade escolar. Após semanas de observação, fomos nos apresentar ao grupo de alunxs LGBTIS+ que estavam no local onde costumavam ficar. Quando souberam do que se tratava a pesquisa, houve muita alegria e a fala do aluno iNò nos marcou, ele disse: Estou feliz por você estar aqui, vai nos ajudar a combater a homofobia na escola.

Após nos apresentarmos, começaram a ocorrer as narrativas destxs alunxs, presentes no decorrer deste trabalho. Quando questionados, se já tinham sofrido algum tipo de preconceito, por conta da sua sexualidade, seja por parte dxs professorxs, dxs funcionários e da própria direção escola, uma das alunas, que se reconhece como pansexual ${ }^{7}$, relatou: Sim, quando a diretora soube que eu estava grávida disse que eu agora precisava me resolver, se queria meninos ou meninas. Respondi a ela que gosto dos dois.

Já o estudante ĩ Q̀ que é gay, quando questionado sobre práticas machistas dentro do espaço escolar, nos informou: "A diretora tem, pois ela permite que um casal heterossexual pode se beijar pelos corredores da escola e um casal homossexual é chamado na coordenação até por andar de mãos dadas".

\footnotetext{
${ }^{7}$ Pessoa que se interessa ou se sente atraída por todos os gêneros sexuais.
} 
Indagamos a outro estudante, se ele já havia presenciado algum caso de homofobia, lesbofobia ou transfobia na escola. A resposta foi: "Fizeram um discurso de ódio na parede do banheiro masculino dizendo que gays tinham que morrer. Fui com um amigo na secretaria da escola reclamar e a diretora disse que não podia fazer nada, pois já tinham pintado o banheiro".

Quando questionadxs sobre o posicionamento da escola em relação a essas práticas homofóbicas e lesbofóbicas, todos os alunos disseram que a direção não toma nenhuma atitude, uma das alunas respondeu: Não há relação com a direção, não se posicionam diante dessas situações.

A homofobia, segundo (Borrillo, 2010, p: 35), đ̂̉aseia-se na mesma lógica utilizada por outras formas de inferiorização, tratando-se da ideologia racista, classista ou antissemita. O objetivo perseguido consiste sempre em desumanizar o outro, em torná-lo inexoravelmente diferenteò isto é, a homofobia parte da não aceitação do outro, do dito r̃diferenteò enquadrando-o como estando fora da m̃ormalidadeò $E$, nesse sentido, 0 conceito de m̃ormalidadeò é construído, implantado, dócil e discretamente nos sujeitos. (Foucault, 2011) alega que a disciplina ñabrica indivíduosòe essa produção se dá num processo de docilidade dos corpos, na tentativa de construção de uma pretensa m̃ormalidadeòentre as pessoas, sem condições de que possam ser diferentes.

A escola produz e reproduz o discurso de poder, disseminando as normas, padrões e regras a serem seguidos por todxs, naturalizando as construções sociais. De acordo com (Nogueira e Nogueira, 2002), além de construir e transmitir conhecimentos, a escola também propaga padrões sociais e perpetua valores. Essa forma de construção molda xs alunxs dento da lógica da normalização do que é ser masculino ou feminino.

Mas antes mesmo da escola, dentro de casa tais valores são produzidos, pois somos e aprendemos a nos comportar como meninos ou como meninas, aprendemos que rosa é cor de meninas e azul de meninos, o futebol é para os garotos, já as coisas de garotas são as bonecas e as maquiagens, e principalmente que homem não chora, dentre outras normas, as quais somos doutrinados desde a infância.

Quando crescemos, essas normas já estão bem internalizadas e somos ensinadxs a jamais quebrá-las, e é aí que a homofobia, a segregação, a exclusão social, dentre outras formas de preconceito e discriminação se constituem. Por isso, xs alunxs que fogem a esses padrões, ou melhor, que enfrentam os padrões, indo na contramão das imposições préestabelecidas, encontram barreiras, não somente na escola, mas também para além dos muros dela.

Atualmente, mesmo com as questões de gêneros e sexualidades, sendo mais debatidas e com grande repercussão na mídia, ainda vivemos em uma sociedade que oprime, fere e em muitos casos matam milhares de LGBTIS+ ou faz com que estxs cometam suicídios, pelo simples fato de serem quem são. $O$ ato de sair de casa, as vezes 
se torna um desafio, quando não se encaixa nos padrões heteronormativos. Ser um LGBTIS+ na escola, é uma tarefa muito difícil também, significa ir contra as normas, que na maioria das vezes são geradas e alimentadas pelo próprio ambiente escolar.

Durante a nossa estadia na escola, realizamos algumas entrevistas com professorxs e funcionárixs, em uma dessas ocasiões uma das diretoras da escola afirmou que xs alunxs LGBTIS+ eram muito violentxs em sua maneira de se auto afirmarem. Segundo ela, o ato de irem com uma faixa na cabeça, com a frase escrito reu sou gayòé uma violência. Este relato nos deu um indício de que existem opiniões conservadoras dentro do espaço escolar em relação axs alunxs LGBTIS+, vindo daquela que deveria protegê-lxs.

$\mathrm{Na}$ maioria das vezes o preconceito vem exatamente de um conceito mal formulado na mente do indivíduo, sendo apenas reproduções de ideias que o acompanham desde o nascimento, prova dessa reprodução, são piadas preconceituosas a respeito dos homossexuais que atravessam gerações e somente tem sentido para aqueles que estão condicionados por um pensamento alienado. (SANTOS, 2012, p. 3).

As normas estão tão impregnadas nas pessoas que o preconceito soa como natural, passa a ser normal o olhar de estranhamento para aquele ou aquela que é diferente. Neste sentido, para aquelxs que vivem segundo os padrões heteronormativos, quem não segue essa lógica é erradx, é tidx como ranormalò por isso precisa urgentemente mudar e abandonar sua r̃anomaliaò

Enquanto a heterossexualidade é definida pelos dicionários (Lê Grand Robert, 1992; Lê Petit Robert, 1996) como a r̃sexualidade (considerada como normal) do heterossexualò e este como aquele r̃que experimenta uma atração sexual (considerada normal) pelos indivíduos do sexo opostoò por sua vez, a homossexualidade está desprovida de tal normalidade. Nos dicionários de sinônimos, nem há o registro da palavra t̃eterossexualidadeò em compensação, termos tais como androgamia, androfilia, homofilia, inversão, pederastia, pedofilia, socratismo, uranisno, androfobia, lesbianismo, safismo e tribadismo são propostos como equivalentes ao de T̃omossexualidadeò $\mathrm{E}$ se Le Petit Robert considera que um heterossexual é simplesmente o oposto de um homossexual, este é designado por uma profusão de vocábulos ${ }^{8}$ : gay, homófilo, pederasta, veado, salsinha, michê, boiola, bicha louca, tia, sandalinha, invertido, sodomita, travesti, lésbica, maria-homem, homaça, hermafrodita, baitola, gilete, sapatão, bissexual. Essa desproporção no plano da linguagem revela uma operação ideológica que consiste em nomear, superabundantemente, aquilo que aparece como problemático e deixar implícito o que supostamente, é evidente e natural. (BORRILLO, 2010, p. 16).

Dentro desta perspectiva, foi possível perceber como a discriminação e o preconceito contra xs alunxs ditos r̃diferentesò foram se desenvolvendo no cotidiano da instituição por nós pesquisada, foi possível ver membros da comunidade escolar que se enquadram nos padrões heteronormativos, humilhando, ameaçando e rindo daquelxs que não se encaixam neste padrão.

${ }^{8} \mathrm{O}$ autor em questão coloca em nota de rodapé que os vocábulos no original são citados como: gay, homophile, pédéraste, enculé, folle, homo, lope, lopette, pedale, pédé, tante, tapette, inverti, sodomite, travesti, travelo, lesbienne, gomorrhéenne, tribade, gouine, bi, à voile et à vapeur. 
Ao longo da história, a escola brasileira estruturou-se a partir de pressupostos fortemente tributários de um conjunto dinâmico de valores, normas e crenças responsável por reduzir à figura do r̃outroò (considerado r̃estranhoò ñnferiorò ñpecadorò r̃̃loenteò ñpervertidoò r̃ rriminosoò ou r̃ contagiosoò) todos aqueles e aquelas que não se sintonizassem com o único componente valorizado pela heteronormatividade e pelos arsenais multifariamente a ela ligados ï centrados no adulto, masculino, branco, heterossexual, burguês, física e mentalmente m̃ormalò (JUNQUEIRA, 2009, p. 14).

\section{CONSIDERAÇÕES FINAIS}

É perceptível que há uma conexão entre o conservadorismo, no que se refere aos valores pessoais e crenças, e as práticas LGBTIfóbicas dentro e fora dos espaços escolares.

Durante o tempo em que estivemos no colégio pesquisado, percebemos, como já dito anteriormente, que ocorrem práticas LGBTIfóbicas no cotidiano da escola, e que há a necessidade de políticas públicas que combatam os preconceitos institucionalizados em nossa sociedade. Tal combate visa o desenvolvimento de novas práticas pedagógicas e capacitação de professorxs, como também de funcionárixs para melhor lidarem com a diversidade de gêneros e sexualidades presente na instituição escolar. Ainda neste sentido, enfatizamos a importância de uma formação capaz de sensibilizar xs docentes e funcionárixs para um olhar de acolhimento as diferenças dxs sujeitxs, que xs ensine a adotar meios e estratégias capazes de impedir ou ao menos diminuir o preconceito e a discriminação.

Existe também uma urgência de alteração dos currículos para que atendam a todxs e não somente aos que se encaixam nos padrões normativos. Portanto, a escola juntamente com a comunidade, deveriam desenvolver projetos que estimulassem a aceitação das diferenças e promover o entendimento sobre o assunto, uma vez que foi possível perceber que muitxs funcionárixs da escola em questão não sabiam o que era homofobia ou tinham uma visão equivocada sobre o assunto.

Acreditamos que ações simples como o estabelecimento de palestras já auxiliam de alguma forma no conhecimento de conceitos como homofobia, por exemplo, e que são de suma importância para aquelxs que atuam no ambiente escolar.

Outro e último ponto a ser destacado nessas considerações, é a atenção em relação as piadas e as situações constrangedoras que envolvem xs estudantes, pois é comum ouvir piadinhas LGBTIfóbicas, pelo fato de um menino ser um pouco mais delicado que os demais ou em relação a menina que não é tão delicada quanto as outras, ou seja, questionando as expressões de gêneros dxs outrxs, só porque estxs fogem aos estereótipos de comportamentos de gêneros já definidos socialmente. 


\section{REFERÊNCIAS}

ALVES, Nilda. Decifrando o pergaminho - o cotidiano das escolas nas lógicas das redes cotidianas. In: OLIVEIRA, Inês Barbosa; (Orgs). Pesquisa no/do cotidiano das escolas: sobre redes de saberes/Rio de Janeiro: DP\&A, 2002.

BONAZZI, Tiziano. Verbete conservadorismo. In: BOBBIO, N.; MATTEUCCI, N.; PASQUINO, G. Dicionário de política/São Paulo: Imprensa Oficial do Estado de São Paulo, 2000.

BORRILO, Daniel. Homofobia: história e crítica de um preconceito. Belo Horizonte: Autentica, 2010.

CROCHÍK, José Leon. Preconceito, Indivíduo e Sociedade. Temas psicol. V .4, n. 3, s/p, 1996.

FACCO, Lucia. A escola como questionadora de um currículo homofóbico. In: SILVA, Joseli Maria. SILVA, Augusto Cesar Pinheiro da (Orgs). Espaço, gênero e poder: conectando fronteiras. Ponta Grossa/Todapalavra, 2011.

FERRARI, Anderson. Você já deve saber sobre minha "orientação sexual" (se não sabia, ficou sabendo agora, hehe) - subjetividades e sujeitos em negociação. In: FERRARI, Anderson. Sujeitos, subjetividades e Educação. Juiz de Fora/UFJF, 2010.

FOUCAULT, Michel. Microfísica do poder. Rio de Janeiro: Graal, 1979.

FOUCAULT, Michel. Os Anormais. São Paulo: Martins Fontes, 2011.

GOFFMAN, Erving. Estigma: notas sobre a manipulação da identidade deteriorada. Rio de Janeiro: LTC, 1988.

GINZBURG, Carlo. Mitos, emblemas e sinais. São Paulo: Companhia das Letras, 1989.

JUNQUEIRA, R. D. (2009). Homofobia nas Escolas: um problema de todos. In R. D. Junqueira (Organizador.), Diversidade sexual na Educação: Problematizações sobre a homofobia nas escolas. Brasília/DF: Ministério da Educação, Secretaria de Educação Continuada, Alfabetização e Diversidade/UNESCO, 2009.

LIBÂNEO, J. C. Didática. São Paulo: Cortez, 1994.

LINS, Beatriz Accioly; MACHADO, Bernardo Fonseca; ESCOURA, Michele. Diferentes, não desiguais: a questão do gênero na escola. São Paulo: Reviravolta, 2016.

LOURO, Guacira Lopes. Gênero, sexualidade e educação: uma perspectiva pósestruturalista./Petropolis, RJ: Vozes, 1997.

LUZ, Luiz Otávio Ferreira da. O menino princesa: gênero e sexualidade na educação infantil. In: SEPULVEDA, Denize; AMARO, Ivan (Orgs). Gêneros, Sexualidades e Educação na Ordem do Dia. Curitiba/CRV, 2018.

NOGUEIRA, Claudio Marques Martins; NOGUEIRA, Maria Alice. A sociologia da educação de Pierre Bourdieu: limites e contribuições. Educação \& Sociedade, ano XXIII, n. 78, p. 15-36, 2002. 
SANTOS, Vanessa. Homossexualidade no Ambiente Escolar. Ensino de sociologia em debate. Revista Eletrônica: LENPS/PIBID de ciências sociais ï UEL. Edição n. 2, Vol. 1, p. 1-17, 2012.

SEPULVEDA, Denize. Emancipação social e exclusão no cotidiano escolar: a homofobia e sua influência nas tessituras identitárias. Rio de Janeiro, 2012. Tese (Doutorado em Educação) - Universidade do Estado do Rio de Janeiro.

SEPULVEDA, José Antonio; SEPULVEDA, Denize. 0 pensamento conservador e sua relação com práticas discriminatórias na educação: $A$ importância da laicidade. Revista Teias, v. 17, n. 47, p. 141-154, 2016. 